\title{
Clinical significance of measuring inflammatory markers in patients with pulmonary arterial hypertension
}

To the Editor Pulmonary arterial hypertension (PAH) is characterized by perivascular inflammatory infiltrates and elevated levels of certain cytokines. ${ }^{1}$ These abnormalities are more advanced in patients with a mutation in the bone morphogenetic protein receptor type 2 (BMPR2), which significantly increases the risk of idiopathic PAH. The BMPR2 mutation has been reported in $11 \%$ to $40 \%$ of subjects with idiopathic $\mathrm{PAH}$, while the dysfunction of the BMPR2 signaling pathway has been observed in all types of PAH. ${ }^{2}$ As the expression of the receptor activator of nuclear factor-кB ligand (RANKL) is induced by BMPR2, a recent study by Jasiewicz et al. ${ }^{3}$ who investigated the role of soluble RANKL (sRANKL) and its decoy receptor, osteoprotegerin (OPG), in patients with PAH is of particular importance. ${ }^{3}$ They showed that the levels of sRANKL and OPG were higher in patients with PAH compared with controls and correlated with markers of disease severity. However, the practical value of their results is still unclear.

Theoretically, some markers of inflammation specific for $\mathrm{PAH}$ could serve as screening tests for this disease in patients with unexplained breathlessness or in high-risk groups such as patients with connective tissue disease, congenital heart disease, portal hypertension, HIV infection, and others. Experimental pulmonary hypertension suggests that altered immunity is a cause rather than consequence of vascular disease; therefore, early detection of $\mathrm{PAH}$-specific inflammatory changes could potentially enable the causal treatment of the disease.

The clinical effect of the modulation of the immune system in patients with $\mathrm{PAH}$ by $\mathrm{PAH}$-specific therapies (prostanoids, endothelin receptor antagonists, and phosphodiesterase inhibitors) is poorly understood. Although the findings from basic science studies are encouraging, clinical studies show unequivocal results. ${ }^{4}$ Recently, we have shown that a 3-month treatment of patients with idiopathic $\mathrm{PAH}$ with specific therapies have not changed the plasma level of interleukin 6, the expression of which is also modulated by BMPR2. ${ }^{5}$ The currently enrolling clinical trials in PAH with molecules such as FK506, rituximab, and anakinra selectively targeting the immune system are promising. In the study by Jasiewicz et al., ${ }^{3} 10$ patients were incident cases who received $\mathrm{PAH}$-targeted therapy at entry to the study. It would be interesting to see whether the levels of OPG and sRANKL changed in this group during the 6-month follow-up.

Finally, different subtypes of PAH are characterized by different mechanisms and inflammatory profiles. The development of PAH associated with congenital heart disease is triggered by mechanical overload of the pulmonary vessels resulting from an increased flow through the pulmonary circulation, while some molecular mechanisms are thought to be involved in the initiation and progression of idiopathic PAH. Jasiewicz et al. ${ }^{3}$ did not report any significant differences in serum OPG and sRANKL concentrations between patients with idiopathic $\mathrm{PAH}, \mathrm{PAH}$ associated with congenital heart disease, and $\mathrm{PAH}$ associated with connective tissue disease. Does it mean that their results can be generalized to the whole PAH population or maybe the numbers of study groups were too small to prove heterogeneity of OPG and RANKL levels in different PAH etiologies?

Author names and affiliations Grzegorz Kopeć, Piotr Podolec (Department of Cardiac and Vascular Diseases, John Paul II Hospital, Jagiellonian University Medical College, Kraków, Poland)

Corresponding author Grzegorz Kopeć, MD, PhD, Oddział Kliniczny Chorób Serca i Naczyń, Krakowski Szpital Specjalistyczny im. Jana Pawła II, ul. Prądnicka 80, 31-202 Kraków, Poland, phone: +48-12-614-33-99, fax: 12-423-43-76, e-mail: g.kopec@uj.edu.pl

Conflict of interest The authors declare no conflict of interest. 


\section{REFERENCES}

1 Rabinovitch M, Guignabert C, Humbert M, Nicolls MR. Inflammation and immunity in the pathogenesis of pulmonary arterial hypertension. Circ Res. 2014; 115: 165-175.

2 Tuder RM, Archer SL, Dorfmüller $\mathrm{P}$, et al. Relevant issues in the pathology and pathobiology of pulmonary hypertension. J Am Coll Cardiol. 2013; 62: D4-12.

3 Jasiewicz M, Knapp M, Waszkiewicz E, et al. Potential pathogenic role of soluble receptor activator of nuclear factor- Bgand and osteoprotegerin in patients with pulmonary arterial hypertension. Pol Arch Med Wewn. 2014; 124: 579-586.

4 Cohen-Kaminsky S, Hautefort A, Price L, et al. Inflammation in pulmonary hypertension: what we know and what we could logically and safely target first. Drug Discov Today. 2014; 19: 1251-1256.

5 Kopeć G, Moertl D, Steiner S, et al. Markers of thrombogenesis and fibrinolysis and their relation to inflammation and endothelial activation in patients with idiopathic pulmonary arterial hypertension. PLoS One. 2013; 8 : e82628. 